\title{
Interaction between Traditional Opera and Movie
}

\author{
Zhequn Zhao \\ Nanjing University of the Arts Institute, Nanjing, China \\ Email: zhao6668@aliyun.com
}

How to cite this paper: Zhao, Z.Q. (2019) Interaction between Traditional Opera and Movie. Open Journal of Social Sciences, 7 , 333-339.

https://doi.org/10.4236/jss.2019.77028

Received: June 28, 2019

Accepted: July 27, 2019

Published: July 30, 2019

Copyright $\odot 2019$ by author(s) and Scientific Research Publishing Inc. This work is licensed under the Creative Commons Attribution International License (CC BY 4.0).

http://creativecommons.org/licenses/by/4.0/

\section{c) (i) Open Access}

\begin{abstract}
When the movie was introduced into China from the West, the traditional opera art had no connection with it. Until the movie "Ding Jun Mountain" had published in 1905, the relationship between traditional opera and movie changed. In China, the two arts began to connect because of some common attributes, and effected their respective development trajectories. When movies just entered into China, the art of traditional opera nurtured the growth of movies, and now the mature art of movie brings new opportunities for the development of traditional opera. In the process of interaction between movie and traditional opera, movie and traditional opera had complement on each other, and constantly enrich and improve their artistic expression. These two arts are constantly merging, forming a subtle relationship, learning from each other, never leaving, and integrating with each other. It is of great significance for the development of traditional opera art in the new media, to analyze the relationship from beginning to the end.
\end{abstract}

\section{Keywords}

Chinese Opera Art, Chinese Film, Martial Arts Movies, Interaction

\section{The "Nurturing" of Traditional Opera to Movies}

On Dec. 28, 1895, You Yi Cun in Xu garden of Shang Hai has shown "Western Movies and Plays" from France. It was the earliest movie screening record in China, and movie art first met with Chinese people. Xu garden's "You Yi Cun" was a theatre for Chinese people to enjoy tea, play and entertainment. Before the movie was shown, "You Yi Cun" had always been the theatre performance venue. It could be said the first foothold was related to opera when the movie came to China.

Before the development of movies, traditional opera has always been the 
mainstream entertainment and leisure mode in China. With the changes of time and culture, people's leisure places have changed from theatres to cinemas, and audiences have changed from amateur performers to movie fans. Although the traditional opera art inherited for thousands of years is gradually faded out of the mainstream, the experienced wealth accumulated in its flourishing Millennium cultivates batch after batch of artistic talents, which affects the development of various forms of art. Movie art is one of them. Many "the first" movies in the history of Chinese movies are inextricably linked with the art of traditional opera, such as the first Chinese movie "Dingjun Mountain", the first feature movie "Die for marriage", the first audio movie "Singing girl Red peony", the first color movie "Vanity Fair" etc. Chinese movies, though not entirely derived from traditional opera, also absorb the essence of traditional opera art. From completely "copying" the artistic form of traditional opera in early movies to the mature period that purposefully and consciously absorbs essence from traditional opera, Chinese movie has never been separated from traditional opera. This is not only the charming attraction of traditional opera art, but also the only way to create the national image of Chinese movie.

There are many similarities between traditional opera and movie, one of which is that both of them have the elements of performance. Chinese opera performing art has its own set of complete system, which shapes the characters to express the plot through singing, reading, doing, fighting. At the beginning of the 20th century, when traditional opera occupied the mainstream cultural position, the vast majority of movie actors/actress and directors crossed the border from the operatic profession to the movie world; therefore the stylistic and freehand performance styles from traditional opera were brought into the movie. For example in the first feature movie "Die for marriage", according to director Zhang Shichuan's memory, he had no concept of "director" at all, and just set up a camera to let the actors perform. There was only one shot in the whole $40 \mathrm{mi}$ nutes, in the same background. It was a black-and-white silent movie without sound effect, and the use of audio-visual language was 0 . It could be seen that whole movie was totally dependent on the performance of the actors. Actors and actress of "Die for marriage" were all from traditional opera stage without exception, they have been trained in basic body skills for many years, and had deeply mark of traditional opera in their temperament. The performance speech of traditional opera seeks to be Beautiful in shape and true in spirit. The body movements of traditional performers are artistically proceeding, with highly fictitious and exaggerated. Undoubtedly, this kind of unique traits from traditional opera have appeared in the pictures of "Die for marriage", also appeared in many other movies at that time. Especially in the period of 1920-1949, the traits of traditional opera performance had a great influence on the creation of movies.

The most significant influence of performing elements from traditional opera to the movie creation was martial arts movie's creation. In the four performing skills of sing, read, do, fight, fight is a unique performing skill. "Fight" on the stage of traditional opera is formed by the integration of traditional martial 
movements, acrobatics and dance etc. of performance. After numerous artistic processing and polishing, the traditional opera martial arts present an artistic appearance of both "martial" and "dance". Chinese movies borrowed the performance skills of traditional opera to and created the performance type of martial arts movies. Like Jia Leilei stated in "The history of Chinese swordsmen movies": "When Chinese movies change from the machine of recording reality" to the "art of telling stories" [1], there are many classical passages that directly absorb the martial arts formula for Beijing Opera. Whether it is to enhance the action, ornamentation of martial arts movies, or to enhance the artistic style of martial arts movies, Beijing opera art is indispensable. Nowadays, martial arts movies have become a famous business card of Chinese movies all over the world. For example, director Xu Ke's "Huang Feihong" series, Ang Lee's "Crouching Tiger, Hidden Dragon" series and Jackie Chan's series are all loved by fans all over the world. These martial arts movies can still see the traces of martial arts skills of traditional opera. The degree of nurturing of traditional opera can be seen.

"Chinese art is different from Western art. It does not imitate nature and resemble nature as the highest realm, but strives to achieve the integration of subject and object, mutual integration, pursuit of life experience full of perceptual life and unique and true feelings of cosmic life." [2] In modern China, traditional opera art is an art model of both refined and popular tastes, occupying the mainstream of people's daily cultural and recreational life. On the stage, the performances of singing, reading, doing and fighting by traditional opera performers bring audiences full of sensory stimulation, while the rituals conveyed by traditional opera stories and the ethics of destiny can arouse audiences' inner resonance.

The art of traditional opera nourishes Chinese movies in an all-round way. Movies not only learned from the performance forms of stage operas, but also incorporate the story subjects and stage shapes of operas into the creation of movies. There are many excellent works in traditional operas. They come from the folk with strong folk interest. Or was born in the writings of literati with full of profound cultural connotation. These masterpieces have gone through the precipitation of years, the processing of artists, and the selection of audiences can be regarded as the cream of traditional opera art, providing abundant resources for topic selection. Movies such as "The Love Eterne", "The romance of West Chamber", "The White Snake", "Chao's Orphan" are all based on traditional opera stories. They can make a great contribution to the international film world as well as the art of traditional opera. "Tian Yi" Movies Company was founded in Shanghai in 1925. Its clear market orientation enabled the movies produced to meet the audience's aesthetic needs. It not only succeeded in commerce, but also led the fashion of ancient costume films in the film industry at that time. After Tian Yi's movies such as "Liang \& Zhu's history" (1926), "Meng Jiangnu" (1926), "Monkey King conquers the Leopard" (1926), "Flirting scholar" (1926), "Legend of White Snake" (1926), "Pearl Tower" (1926) and so on, which 
earned high box-office revenues, other movie's companies in Shanghai were similar in succession. From the title of the movie, we could peep a little, most of these ancient costume movies are adapted from traditional opera stories. The actors/actress costumes, costumes and even props in the movie are directly used of modeling means of the traditional opera stage. The nurturing of traditional opera to movies has penetrated into all aspects of film creation. At present, we can still see the shadow of traditional opera in the movies with ancient costumes. For example, "Green Snake" which directed by Xu Ke, the story is based on the story of "The White Snake" in traditional operas, and the traits in the movie also draw on the makeup of female role in a play in Beijing opera. In a word, the study of Chinese movie on opera art is pluralistic and comprehensive, with the support of traditional opera, domestic movies find their own image styles and aesthetic presentation, enhance their artistic appeal, and bring a "Chinese style" to the world's movie industry. Absorbing the essence of traditional opera art, Chinese movies have gradually matured. On the contrary, the cross-border and integration of "movie" and "traditional opera" have not only realized the inheritance and development of traditional operas, but also created opportunities for them to get out of the current development predicament and flourish again.

\section{Movie Fed Back to Traditional Opera}

Since our country was able to shoot movies independently, we could find the shadow of opera in almost every period of classical movies. From the perspective of movie's development, this is the "nurturing" of traditional opera art to movie, but if we look at this phenomenon from the perspective of traditional opera, the traditional opera elements in movie works are the dissemination and promotion of this traditional art. That so-called "back-feeding" of movie art to traditional opera art is embodied in this.

Master Mei Lanfang was one of the few artists that explore the integration of traditional opera and movie. In 1920, he made two movies in Shanghai, "Poeny paviliion" and "the female spread a flower". As a movie, the two movies innovatively used the movie skills of reduplication, known as the transition from traditional Chinese opera documentary to traditional Chinese opera feature movie. But for the art of traditional opera, the two movies have far more significance than these. Mei Lanfang was 26 years old at that moment, which was the "raising period" of his performing art. The movie recorded and kept his excellent stage performance faithfully, and became an important material for future generations to learn and study. After that, Mei Lanfang cooperated with Min Xin movie's company to shoot the sword dance of "Farewell My Concubine", the dust-blowing dance of "Madame Shangyuan", the playing military roles of "Mulan Enlisted", the flower funeral of "Legend of Lin DaiYu", and the 5 short movies not only recorded Mei Lanfang's body movements but also included stage appearance, and became a later generation to understand the traditional opera in the early $20^{\text {th }}$ century. When Mei Lanfang visited Japan in 1924, he was invited to shoot 2 clips which are fighting with wooden sling of "Neon Pass" and prick 
the mussel of "Lian Jinfeng". In 1930, when he went to the United States, he was filmed 2 clips of "Thorn tiger" by Paramount Film company. Theses 3 clips of traditional opera were done by Mei Lanfang that cooperated with overseas movie's company, as for propaganda movies and news, which embodies another function of movie to traditional opera besides recording-Communication function. These movies showed traditional operas to foreign audiences, which not only made Mei Lanfang famous worldwide, but also promoted Chinese traditional culture to the world.

The documentary and communicative nature of the movie have a far-reaching impact on the art of traditional opera. Whether it is a documentary of traditional opera loyal to the stage performance or a feature movie of traditional opera processed and reconstructed by means of movie, audio-visual means, it is a powerful carrier to retain and disseminate the art of traditional opera. Traditional opera art belongs to the folk. In the past, mobile theatre clubs were often engaged in traditional opera performances, mainly performing in some places during festivals and celebrations. At the end of a performance in one place, they turn to other places for performance, that audience could only wait for the next festival if they missed the show. The integration of movie and traditional opera has brought about a new mode of transmission of traditional opera. Many classic repertoires and actor's distinctive performance have been recorded by cameras, people can watch opera performances repeatedly on the screen, which meets the needs of the theatre. And with the establishment of cinemas and the formation of folk projection teams, the spread of movies has become widespread, and traditional opera have gained greater performance space. In the old days, mobile theatre seldom rehearsed new plays. A tour around the theatre lasted for several years, and actors/actress could settle down by practicing one or two "extraordinary activities". Long-term repetition of performances made performers physically and mentally exhausted, resulted in actors/actress slack performance were not conducive to the development of traditional opera. Traditional opera movies break the old situation of opera communication, with the help of movies, people can easily enjoy excellent opera performances, which undoubtedly brings great challenges to the performers and teams engaged in the art of opera. In order to attract audiences and seize the market for economic benefits, they have to create new plays, exquisite acting skills, and actively develop the art of opera.

With the social transformation and economic development, the traditional opera art is gradually away from the popular aesthetic fashion, and gradually out of its mainstream cultural status. The flourishing age of traditional opera has gradually disappeared, because of the lack of audience and the potential demand of commercial movie market, there are fewer and fewer traditional opera movies. But this does not mean the movie art abandons the traditional opera art, on the contrary, the integration of movie and traditional movie shows vigorous vitality in another style. Since the new century, there has been such kinds of feature movies in Chinese movie circles, which either expresses the life experience inside and outside the traditional opera with the famous artists in the operatic 
profession, or reproduces the traditional opera story in a new way with the traditional opera text as the object of adaptation, or presents the traditional opera as an element in the movie bridge. Such as "Farewell My Concubine", "Mei Lanfang" and "Zhao's Orphan" directed by Chen Kaige, "Raise the Red Lantern" and "A Simple Noodle Story" directed by Zhang Yimou, "My Kingdom" directed by Gao Xiaosong and so on. Although these movies are not strictly opera movies, but it does not hinder its ability to disseminate and promote the traditional opera culture. This kind of movie has a strong commercial nature, they publicize traditional art to the public under the banner of promoting traditional art, attracting audiences to the cinema. It is undeniable that these movies are often well-made, and they are just right for the performance of the traditional opera and have profound implications. Audience are attracted by the theatrical art on the screen when they watch movies, such as the movie "Farewell My Concubine" which depicts the performance of the traditional opera, the fate of the actors in the play, and the rise and fall of the pear orchard. Once released, it attracts worldwide attention and won The Golden Palm Award of Festival de Cannesl. With the help of movies, the art of traditional opera attracts the public's attention once again, which made more and more people appreciate the unique charm of traditional Chinese opera art and arouses their interest in traditional opera.

In the context of the decline of traditional opera art, the decline of actors/actress and audience, and the increasing lack of opera-watching literacy, the significance of opera communication is far greater than the inheritance of traditional opera. Thanks to the long infiltration and integration between movie and traditional opera, movie art has incomparable advantages in accuracy, breadth and depth in the dissemination of traditional opera. Traditional operas and Chinese movies have been going hand in hand for more than a century. Although they have gone through ups and downs, their mutual influence has remained unchanged. Faced with their different living conditions, traditional operas and Chinese movies should find their own role orientation more clearly in their relationship to adapt to the times, and clearly understand what kind of help the other party can give themselves, take what they need, and take what they need. For a long time, their mutual influence will continue.

In the process of interaction between movie and traditional opera, movie and traditional opera had complement on each other, and constantly enrich and improve their artistic expression. The two arts are continually integrated, a delicate relationship has emerged, that is to learn from each other, never leave of forsaking, blend with each other. It is of great significance for the development of traditional opera art in the new media, to analyze the relationship from beginning to the end. Through the joint efforts of traditional opera artists and movie artists, martial arts movie and traditional opera movie have become unique types of movies, but the relationship between Chinese movie and Chinese traditional opera goes far beyond that. By sorting out the lens vocabulary and movie aesthetics in early martial arts movies and traditional opera's movies, it has the guidance of 
the role for how Chinese movie expresses ethnic aesthetics, in the new period of rapid innovation of movie technology.

\section{Conflicts of Interest}

The author declares no conflicts of interest regarding the publication of this paper.

\section{References}

[1] Jia, L.L. (2005) The History of Chinese Swordsmen Movies. Culture \& Art Publishing House, 43.

[2] Ouyang, W.F. and Yang, C.Q. (2006) On the Artistic Conception and Creation of Contemporary Chinese Movies. Creation and Review, No. 2, 13-17. 